\title{
Farelerde Pentilentetrazol ile Oluşturulan Epileptik Nöbetler Üzerine Anakinra'nın Etkisinin Araştırılması
}

\author{
Investigation of the Effect of Anakinra on Pentylenetetrazole-Induced Epileptic Seizures \\ in Mice
}

Ahmet Kemal FILIZ ${ }^{1}$ (D) Sebahattin KARABULUT ${ }^{2}$

öZ:

Amaç: Beyinde gama aminobutirik asit (GABA) ve glutamat arasındaki dengenin bozulması, nöbet oluşumuna ve epileptogeneze katkı sağlayan önemli faktörlerden biridir. Bu çalışmanın amacı, anakinra ön tedavisinin pentilentetrazol (PTZ) ile oluşturulan nöbet modelinde kortikal ve hipokampal GABA ve glutamat seviyeleri üzerine etkisinin olup olmadığını belirlemektir.

Araçlar ve Yöntem: Çalışmada 18 adet BALB-c türü fare Kontrol, PTZ ve Anakinra grupları şeklinde 3 gruba ayrıldı. Nöbetleri başlatmak için $60 \mathrm{mg} / \mathrm{kg}$ dozda PTZ enjeksiyonu farelere intraperitonal olarak uyguland. Anakinra grubuna PTZ enjeksiyonundan 30 dakika önce intraperitonal olarak anakinra $(100 \mathrm{mg} / \mathrm{kg})$ uygulandı. Hayvanların kortikal ve hipokampal GABA ve glutamat düzeyleri Enzyme Linked Immunosorbent Assay (ELISA) yöntemi kullanılarak ölçüldü.

Bulgular: PTZ'nin neden olduğu nöbetler, hipokampusta glutamat seviyesini artırırken ( $<<0.001)$, GABA düzeyinde azalmaya yol açtı $(p<0.05)$. PTZ tedavisi kortikal glutamat seviyesini arttırdı $(p<0.05)$. Anakinra ile ön tedavi hipokampusta glutamat düzeyini azaltırken $(\mathrm{p}<0.001)$, GABA düzeyinde artışa yol açtı $(\mathrm{p}<0.01)$. Ayrıca anakinra ön tedavisi kortikal glutamat seviyesini azaltırken $(\mathrm{p}<0.05)$, GABA düzeyinde artışla sonuçlandı $(\mathrm{p}<0.001)$.

Sonuç: PTZ'nin neden olduğu nöbetler beyinde GABA düzeyinin azalmasına ve glutamat seviyesinin artışına neden olmaktadır. PTZ enjeksiyonu öncesinde anakinra tedavisi farelerin beyinlerinde uyarılma lehine bozulmuş GABA/Glutamat dengesizliğini iyileştirmektedir.

Anahtar Kelimeler: anakinra; GABA; glutamat; pentilentetrazol

\section{ABSTRACT:}

Purpose: Disruption of the balance between gamma aminobutyric acid (GABA) and glutamate in the brain is one of the important factors contributing to seizure formation and epileptogenesis. The aim of this study is to determine whether anakinra pretreatment has an effect on cortical and hippocampal GABA and glutamate levels in a seizure model induced with pentylenetetrazole (PTZ).

Materials and Methods: In the study, 18 BALB-c type mice were divided into 3 groups as Control, PTZ, and Anakinra groups. An injection of $60 \mathrm{mg} / \mathrm{kg} \mathrm{PTZ}$ was administered intraperitoneally to mice to induce seizures. Anakinra group was administered intraperitoneally $(100 \mathrm{mg} / \mathrm{kg}) 30$ minutes before PTZ injection. The cortical and hippocampal GABA and glutamate levels of the animals were measured using the Enzyme Linked Immunosorbent Assay (ELISA) method.

Results: PTZ-induced seizures led to a decrease in the hippocampal GABA level ( $<<0.05)$, while the glutamate level increased $(\mathrm{p}<0.001)$. The treatment of PTZ also increased the level of cortical glutamate $(\mathrm{p}<0.05)$. The pretreatment with anakinra led to a decrease in the hippocampal glutamate level $(\mathrm{p}<0.001)$, but increased GABA level $(\mathrm{p}<0.01)$. In addition, the pretreatment with anakinra cause to decrease the level of cortical glutamate $(\mathrm{p}<0.05)$, while the GABA level increased $(\mathrm{p}<0.001)$.

Conclusion: PTZ-induced seizures cause a decrease in GABA levels and an increase in glutamate levels in the brain. Anakinra treatment prior to PTZ injection ameliorates the GABA/Glutamate imbalance that has shifted to the excitation side in the brains of mice.

Keywords: anakinra; GABA; glutamate; pentylenetetrazole 


\section{GíRIŞ}

Epilepsi, dünya nüfusunun yaklaşık olarak \% 0.5-1'ini etkileyen yaygın nörolojik bozukluklardan biridir. ${ }^{1}$ Hastalık, kendiliğinden ortaya çıkan tekrarlayıcı nöbetlerle karakterizedir. Beyinde uyarıc1 ve inhibe edici sinirsel aktivite arasındaki dengenin bozularak, uyarıcı nöronların lehine kayması sonucu nöbet oluştuğu bilinmektedir. ${ }^{2}$ Antiepileptik ilaçlar (AEİ) nöbetleri baskılarken, hastalık üzerinde tamamen iyileşme sağlayamazlar. Bununla birlikte, mevcut AEI'lar hastaların yaklaşık olarak üçte birinde etkisizdir. ${ }^{3}$ İlaca dirençli grup olarak tarif edilen bu hasta grubunda alternatif bir seçenek olarak cerrahi tedavi yer almaktadır. Dahası, hem hastalığın kendisi hem de kombine olarak kullanılan AEI'lar bilişsel bozukluklara yol açabilmektedir. ${ }^{4}$ Bu nedenle, epilepsi ile mücadelede etkin alternatif tedaviler için daha fazla araştırmaya ihtiyaç duyulmaktadır.

İnflamasyon homeostazı koruyan fizyolojik bir yanıtken, anormal ve uzun süreli inflamasyon organizmalar için patolojiktir. Nöroinflamasyon, nöronlarda ortaya çıkan inflamatuvar aktiviteleri içerir. Nöroinflamasyonun epilepsi gibi beyin hastalıklarının patogenezinde yer aldığı ve epileptogenez sürecine katk1 sağladığı bilinmektedir. ${ }^{5}$ Öyle ki, bazı spesifik inflamatuvar mediyatörlerin ve bunların reseptörlerinin epileptik beyin dokusunda upregüle olduğu son yıllarda yapılan çalışmalarda gösterilmiştir. ${ }^{6,7}$ Proinflamatuvar sitokinler olarak bilinen bu proteinler immün sistemin sinyal molekülleri olarak tanımlanırlar. Bu sinyal moleküllerinden "interlökin-1 reseptör/Toll-benzeri reseptör (İL-1R/TLR)" yolağının çeşitli epilepsi modellerinde aktive olduğu gösterilmiştir. ${ }^{8-9}$ Dolayısıyla bu sinyal yolağının baskılanmasıyla ortaya çıkan antikonvülsan etkinin, ilaca-dirençli epileptik olgularda nöbetlerin önlenmesinde bir araç olarak kullanılabileceği ön görülmektedir. ${ }^{9}$

Anakinra, İL-1 $\beta$ 'in biyolojik etkilerini inhibe eden İL-1 reseptör tip 1 (IL-1R1)'in rekombinant bir versiyonudur. ${ }^{10}$ Anakinra, yenidoğan ve çocuklardaki otoinflamatuvar hastalıkları tedavi etmek için onaylanmış bir ajandır. ${ }^{11}$ Anakinra'nın, ilaca dirençli epilepsi hastalarında steroidlere ya da AEI'lara yanıt vermeyen nöbetleri önemli ölçüde azalttığı gözlenmiştir. ${ }^{12,13}$ Anakinra'nın antiepileptik etkinliğinin epilepsi hayvan modelinde araştırıldığı bir çalışmada da, bu rekombinant İL-1R antagonistinin (ILL-1Ra) intrahippokampal uygulamasının, farelerde GABA-A reseptör antagonisti bikukulinin neden olduğu epileptik nöbetleri güçlü bir şekilde inhibe ettiği rapor edilmiştir. ${ }^{12}$ Normal bir beyinde, uyarıcı ve inhibe edici nörotransmitter sistemleri arasında aşırı elektriksel aktiviteleri kontrol altında tutan bir denge bulunmaktadır. Bu denge, beynin sırasıyla iki ana uyarıcı ve baskılayıcı nörotransmitteri olan GABA ve glutamat tarafindan temsil edilmektedir. Dengenin uyarıcı sistem tarafına kayması spontan nöbetlerin oluşumuyla ilişkilidir ve bu nörotransmitter düzeylerinin ölçülerek GABA/Glutamat balansının değerlendirilmesi epilepsi araştırmalarında yaygın olarak kullanılmaktadır. ${ }^{13} \mathrm{Bu}$ çalışmada amacımız, farelerde PTZ ile oluşturulan nöbet modelinde anakinra uygulamasının GABA/Glutamat dengesi açısından nöbetler üzerine etkisini araştırmaktır.

\section{ARAÇLAR ve YÖNTEM}

\section{Deney Hayvanları}

Çalışmada standartlara uygun kafeslerde bakımı yapılan 18 adet, 4-5 aylık, 30-33 gr ağırlığındaki BALB-c albino fare kullanıldı. Fareler $22 \pm 1{ }^{\circ} \mathrm{C}$ oda sıcaklığında, 12 saatlik aydınlık/karanlık siklusunun sağlandığı, sesten yalıtılmış odada ve $\% 55 \pm 6$ oranda nemli ortamda tutuldu. Farelerin yem ve su ile beslenmelerinde herhangi bir kisitlama yapılmadı. Çalışma Temmuz 2020-Ağustos 2020 tarihleri arasında gerçekleştirildi. Çalışma için Sivas Cumhuriyet Üniversitesi hayvan deneyleri etik kurulundan onay alındı (Karar No: 65202830-050.04.04-421 Tarih: 22.07.2020).

\section{Çalışmada Kullanılan Kimyasallar}

PTZ ( Sigma-Aldrich, USA) ve Anakinra (Kineret, 100 $\mathrm{mg} / 0.67 \mathrm{ml}$ çözelti) üretici firmadan temin edildi. Kimyasallar serum fizyolojik $(10 \mathrm{~mL} / \mathrm{kg})$ içinde çözülerek farelere intraperitonal (i.p.) olarak uyguland.

\section{Deneysel Protokol}

Çalışmada, hayvanlar her grupta 6 fare olarak şekilde rastgele 3 gruba ayrıldı:

1. Kontrol; Herhangi bir işlem uygulanmayan grup, 


\section{PTZ; PTZ ile nöbet indüklenen grup,}

3. Anakinra; PTZ ile nöbet indüklemeden 30 dakika önce $100 \mathrm{mg} / \mathrm{kg}$ dozda ${ }^{14}$ anakinra uygulanan grup.

Nöbet indüklemek için, farelere $60 \mathrm{mg} / \mathrm{kg}$ tek $\operatorname{doz}^{15} \mathrm{PTZ}$ i.p. olarak enjekte edildi. Enjeksiyonu takiben epileptik nöbet davranışları gözlenen bütün hayvanlar 24 saat sonra feda edildi. Aseptik cerrahi koşullarda korteksleri ve hipokampusları çıkarıldı ve ileri biyokimyasal analizler için uygun koşullarda saklandı.

\section{Biyokimyasal Analizler}

Kortikal ve hipokampal doku örnekleri soğuk PhosphateBuffered Saline (PBS) çözeltisi (pH 7.4) içinde homojenize edildi ve $12000 \mathrm{~g}$ 'de 10 dakika boyunca $4{ }^{\circ} \mathrm{C}$ 'de santrifüje edildi. Daha sonra üst faz GABA ve glutamat düzeylerinin eliza yöntemiyle ölçülmesinde kullanıldı. Doku örneklerinde total protein ölçümü Bradford yöntemine göre yapıld1. ${ }^{16}$ GABA ve glutamat düzeylerinin belirlenmesinde ticari eliza kiti (YL Biont, Shanghai, China ) kullanildi.

\section{İstatistiksel Analiz}

Veriler "ortalama \pm ortalamanın standart hatası (SEM)" olarak sunuldu. İstatistiksel analiz için SPSS istatistik programı (IBM SPSS Statistical Software Version 22.0 [IBM, Armonk, NY, ABD]) kullanıldı. İlk olarak verilerin normal dağılıma uygunluk gösterip göstermediğini değerlendirmek için Kolmogorov-Smirnov testi uygulandı. Daha sonra verilerin gruplar arası karşılaştırılması "tek yönlü varyans analizi ile (One way ANOVA)” ve post-hoc Tukey testi ile gerçekleştirildi. İstatistiksel anlamlılık $\mathrm{p}<0.05$ olarak tanımlandı.

\section{BULGULAR}

PTZ ile nöbet oluşumundan sonra grupların korteksindeki GABA ve glutamat konsantrasyonları Şekil 1'de gösterildi. Kortikal GABA düzeylerinin Anakinra grubunda anlamlı olarak yüksek olduğu gözlendi $(\mathrm{p}<0.001)$. Kortikal glutamat seviyelerinde ise hem PTZ hem de Anakinra gruplarında anlamlı farklılıklar elde edildi $(\mathrm{p}<0.05)$.
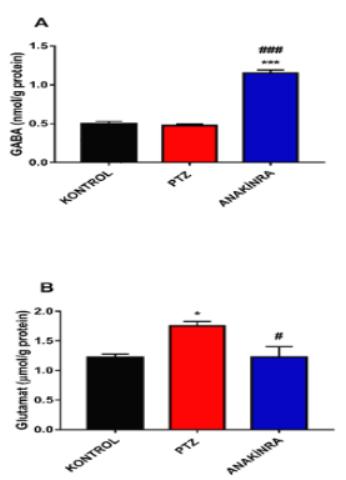

Şekil 1. Anakinra ön tedavisinin PTZ ile oluşturulan nöbet sonrası kortekste GABA (A) ve glutamat (B) düzeylerine etkisi. Veriler ortalama \pm SEM olarak verilmiştir. $(n=6) .{ }^{*} \mathrm{p}<0.05, * * * \mathrm{p}<0.001$, Kontrol grubuyla karşılaştırıldığında; $\# \mathrm{p}<0.05$, \#\#\#p<0.001 PTZ grubuyla karşılaştırıldığında.

PTZ ile nöbet oluşumu sonrası grupların hipokampusundaki GABA ve glutamat konsantrasyonları Şekil 2'de gösterildi. Hipokampal GABA düzeyi PTZ grubunda azalırken ( $\mathrm{p}<0.05)$, anakinra uygulanan grupta yüksek bulundu $(\mathrm{p}<0.01)$. Benzer şekilde, hipokampal glutamat düzeyleri PTZ grubunda yüksek, anakinra tedavisi alan grupta düşük olarak gözlendi $(\mathrm{p}<0.001)$.
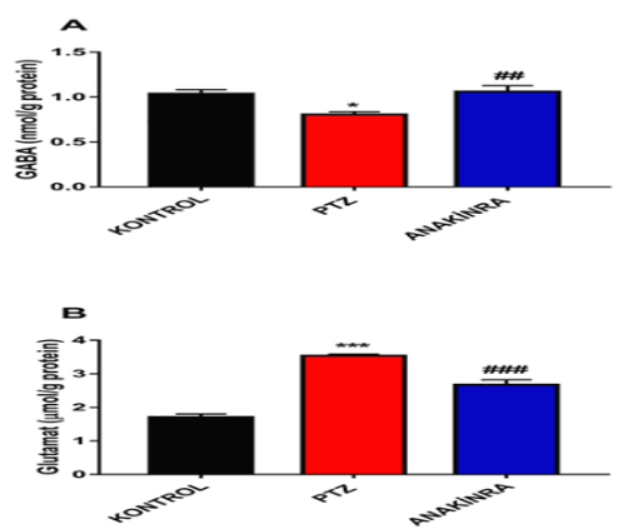

Şekil 2. Anakinra ön tedavisinin PTZ ile oluşturulan nöbet sonrası hipokampusta GABA (A) ve glutamat (B) düzeylerine etkisi. Veriler ortalama \pm SEM olarak verilmiștir. $(n=6) . * p<0.05$, $* * * \mathrm{p}<0.001$, Kontrol grubuyla karșılaştırıldığında; \#\#p $<0.01$, \#\#\#p<0.001 PTZ grubuyla karşılaştırıldığında.

\section{TARTIŞMA}

Son y1llarda elde edilen klinik ve deneysel kanıtlar, beyindeki inflamatuvar süreçlerin nöbetlerin ve epilepsinin patofizyolojisinde yer alan bir mekanizma olabileceği hipotezine güçlü bir destek sağlamıştır. ${ }^{5}$ İ-1 $\beta$ gibi, bu sürecin ana aktörleri olan proinflamatuvar sitokinler nöbetlerin 
önlenmesinde ve epilepsinin tedavisinde önemli hedefler olarak tanımlanmaktadır. ${ }^{7}$ Bu çalışmada, ILL-1 $\beta$ reseptör antagonisti anakinra ön tedavisinin PTZ ile indüklenen nöbet sonrası korteks ve hipokampustaki GABA ve glutamat konsantrasyonlarına etkisi araştırılmıştır.

Proinflamatuvar sitokinler, hem fizyolojik hem de patofizyolojik koşullarda hücreler arası iletişimin kritik elemanlarıdırlar. Bu sitokinlerden İL-1ß'nın bazı merkezi sinir sistemi hastalıklarının patofizyolojisinde önemli bir rol oynadığına dair kanıtlar vardır. ${ }^{17} \mathrm{Bu}$ sitokinin kemirgenlerin ön beyin bölgelerinde çeşitli nörotransmitterlerin sal1verilmesini düzenlediği, böylece sinaptik iletiyi ve iyon akımlarını değiştirerek nöronal uyarılabilirliği etkilediği gösterilmiştir. ${ }^{18-19}$ Konvülsan uyarılar kemirgenlerin merkezi sinir sistemlerinde İL-1 $\beta$ 'nın yanı sıra, onun endojen reseptör antagonisti olan İL-1Ra'nın da artışına yol açar. ${ }^{20}$ İL-1Ra'nın rekombinant ürünü olan anakinra, yenidoğanların ve çocukların çeşitli otoimmün hastalıklarının tedavisinde kullanılan bir ajandır. ${ }^{21}$ Anakinra'nın antikonvülsan özelliği olduğu önceki çalışmalarda gösterilmiştir. ${ }^{12}$ Çalışmamızda, bir GABA-A reseptör antagonisti olan PTZ ile nöbet indüklenmesinden sonra, hipokampusta GABA konsantrasyonunun azalmış olduğunu gözlemledik. Bunun aksine, nöbet sonrası hipokampal ve kortikal glutamat düzeyleri yüksek olarak elde edildi. Eksitatör ve inhibitör ana nörotransmitterler arasındaki denge normal bir beyin fonksiyonu için elzemken, GABA/Glutamat imbalansı epilepsiyle yakından ilişkilidir. ${ }^{22-23} \mathrm{PTZ}$ enjeksiyonları sonrası hipokampusta GABA konsantrasyonunun azalmış olması literatürle uyumludur. ${ }^{24-25}$ PTZ'nin beyinde GABA ve Glutamat konsantrasyonları üzerindeki etkisini, bu nörotransmitterlerin metabolizmasında yer alan glutamat dehidrogenaz ve GABA aminotransferaz gibi enzimlerin aktivitelerini etkileyerek gerçekleştirdiği ileri sürülmektedir. ${ }^{26} \mathrm{PTZ}$, GABA aminotransferazı stimüle ederek ortamdaki GABA miktarını azaltmaktadır. Bununla birlikte, Anakinra ön tedavisi PTZ’nin indüklemiş olduğu kortikal ve hipokampal GABA düzeylerindeki azalmayı sınırlamıştır. Bu sonuç, anakinranın antikonvülsan özelliğine işaret etmektedir. Nöronal aktivite üzerine IL-1ß'nın etkisini gösteren invitro çalışmalarda, bu sitokinin hipokampal CA3 bölgesinde GABAerjik iletimi baskıladığı, hipokampal CA1 bölgesinde ise glutamerjik sinyali artırdığı gösterilmiş- tir. ${ }^{27-28}$ PTZ'nin yol açtığı nöbet sonrası kortekste ve hipokampüste gözlemlenen glutamat artışı önceki çalışmalarla uyumludur. ${ }^{29-30}$ PTZ, glutamat dehidrogenezi inhibe ederek glutamat konsantrasyonunda artışa yol açmaktadır. ${ }^{26}$ Dolayısıyla, PTZ ile GABAerjik sistemin inhibe edilirken glutamerjik sistemin aktive edilmiş olması, GABA/Glutamat dengesini uyarılma lehine kaydırarak nöbetlere yol açmaktadır. Buna karşılık, anakinra ön tedavisinin beynin bu bölgelerindeki glutamat artışını sınırladığı gözlenmektedir. Status epileptikusun neden olduğu aşırı glutamat sal1mının, NMDA gibi glutamat reseptörlerinin aşırı uyarılmasına yol açarak, kendiliğinden oluşan nöbet aktivitesine ve nöbet kaynaklı beyin hasarı gelişimine yol açtığı rapor edilmiştir. ${ }^{31}$ Glutamerjik sinyali modüle edebilen terapötik yaklaşımların epilepsinin kalıcı olarak tedavi edilmesinde önemli bir rol oynayabileceği düşünülmektedir.

Önceki çalışmalarda anakinra'nın antikonvülsan etki mekanizması İL-1Ra aracılı inflamasyon yolağı üzerinden açıklasa da, ${ }^{12}$ bu ajanın aynı zamanda beyindeki GABA/Glutamat dengesini düzenleyerek etki etmesi olasıdır. İL-1 $\beta$ 'nın beyinde hem eksitatör hem de inhibitör nörotransmitter moleküllerin salıverilmesini modüle etmesi, anakinra'nın bu olası etki mekanizmasına işaret etmektedir. Anakinra antikonvülsan etkisini, beyinde GABA düzeyinde azalma veya glutamat düzeyinde artma gibi nöbet oluşumuna yol açan süreçleri engelleyerek gösteriyor olabilir. Anakinra'nın bu etkisini kanıtlamak için hem NMDA, AMPA gibi glutamat reseptörlerinin hem de GABA-A, GABA-B gibi GABA reseptörlerinin ekpresyonlarının düzenlenmesini de içine alan çalışmalara ihtiyaç duyulmaktadır. Öte yandan, anakinra uygulamasının ilgili beyin bölgelerinde İL-1 $\beta$ düzeylerine etkisinin belirlenmesi, ilacın nöroinflamasyonu modülasyonu hakkında fikir vererek antiepileptik özelliğinin daha iyi anlaşı1masına katkı sağlayacaktır. Sadece anakinra tedavisi uygulanan bir deney grubunun olmaması çalışmamızın diğer bir eksikliğidir. Ayrıca, anakinra ön tedavisinin tek doz PTZ ile indüklenen akut nöbet modelindeki etkisinin yanında, çoklu PTZ enjeksiyonlarının yapıldığı tutuşma modelinde anakinra'nın eş zamanlı ya da nöbet sonrası uygulanacağı çalışmalar epileptogenez sürecine olan etkisini görmek bakımından önemli olacaktır. 


\section{Çıkar Beyannamesi}

Yazarlar, herhangi bir çıkar çatışmasının olmadığını beyan etmektedirler.

\section{Araştırmacıların Katkı Oranı Beyanı}

Ana fikir/Planlama: AKF. Veri toplama/İşleme: AKF. Veri analizi ve yorumlama: SK. Literatür taraması: AKF. Yazım: SK. Gözden geçirme ve düzeltme: AKF. Danışmanlık: AKF, SK.

\section{KAYNAKÇA}

1. Taskıran AS, Ergul M, Gunes H, Ozturk A, Sahin B, Ozdemir E. The Effects of Proton Pump Inhibitors (Pantoprazole) on Pentylenetetrazole-Induced Epileptic Seizures in Rats and Neurotoxicity in the SH-SY5Y Human Neuroblastoma Cell Line. Cell Mol Neurobiol. 2020;41(1):173183.

2. Sharma R, Leung WL, Zamani A, O'Brien TJ, Casillas Espinosa PM, Semple BD. Neuroinflammation in Post-Traumatic Epilepsy: Pathophysiology and Tractable Therapeutic Targets. Brain Sci. 2019;9(11):318.

3. Löscher W, Potschka H, Sisodiya SM, Vezzani A. Drug Resistance in Epilepsy: Clinical Impact, Potential Mechanisms, and New Innovative Treatment Options. Pharmacol Rev. 2020;72(3):606-638.

4. Narayanan J, Simon KC, Choi J, et al. Factors Affecting Cognition and Depression in Adult Patients with Epilepsy. J Epilepsy Res. 2019;9(2):103-110.

5. Vezzani A, French J, Bartfai T, Baram TZ. The role of inflammation in epilepsy. Nat Rev Neurol. 2011;7(1):31-40.

6. De Vries EE, van den Munckhof B, Braun KP, van RoyenKerkhof A, de Jager W, Jansen FE. Inflammatory mediators in human epilepsy: A systematic review and metaanalysis. Neurosci Biobehav Rev. 2016;63:177-190.

7. Vezzani A, Balosso S, Ravizza T. Neuroinflammatory pathways as treatment targets and biomarkers in epilepsy. Nat Rev Neurol. 2019;15(8):459-472.

8. Maroso M, Balosso S, Ravizza T, Liu J, Bianchi ME, Vezzani A. Interleukin-1 type 1 receptor/Toll-like receptor signalling in epilepsy: the importance of IL-1beta and highmobility group box 1. J Intern Med. 2011;270(4):319-326.

9. Vezzani A, Maroso M, Balosso S, Sanchez MA, Bartfai T. IL-1 receptor/Toll-like receptor signaling in infection, inflammation, stress and neurodegeneration couples hyperexcitability and seizures. Brain Behav Immun. 2011;25(7):1281-1289.

10. Dinarello CA, Simon A, van der Meer JW. Treating inflammation by blocking interleukin-1 in a broad spectrum of diseases. Nat Rev Drug Discov. 2012;11(8):633-652.

11. Pascual V, Allantaz F, Arce E, Punaro M, Banchereau J. Role of interleukin-1 (IL-1) in the pathogenesis of systemic onset juvenile idiopathic arthritis and clinical response to IL-1 blockade. J Exp Med. 2005;201(9):1479-1486.

12. Vezzani A, Moneta D, Conti M, et al. Powerful anticonvulsant action of IL-1 receptor antagonist on intracerebral injection and astrocytic overexpression in mice. Proc Natl Acad Sci U S A. 2000;97(21):11534-11539.

13. Yan Veenendaal TM, Backes WH, Tse DHY, et al. High field imaging of large-scale neurotransmitter networks: Proof of concept and initial application to epilepsy. Neuroimage Clin. 2018;19:47-55.

14. Dyomina AV, Zubareva OE, Smolensky IV, et al. Anakinra Reduces Epileptogenesis, Provides Neuroprotection, and Attenuates Behavioral Impairments in Rats in the Lithium-
Pilocarpine Model of Epilepsy. Pharmaceuticals (Basel). 2020;13(11):340.

15. Taştemur Y, Gumus E, Ergül M, et al. Positive effects of angiotensin-converting enzyme (ACE) inhibitor, captopril, on pentylenetetrazole-induced epileptic seizures in mice. Trop $\mathrm{J}$ Pharm Res. 2020;19(3):637-643.

16. Ernst O, Zor T. Linearization of the bradford protein assay. J Vis Exp. 2010;38:1918.

17. Mendiola AS, Cardona AE. The IL- $1 \beta$ phenomena in neuroinflammatory diseases. J Neural Transm (Vienna). 2018;125(5):781-795.

18. Rothwell NJ, Hopkins SJ. Cytokines and the nervous system II: Actions and mechanisms of action. Trends Neurosci. 1995;18(3):130-136.

19. Patel RR, Khom S, Steinman MQ, et al. IL-1 $\beta$ expression is increased and regulates GABA transmission following chronic ethanol in mouse central amygdala. Brain Behav Immun. 2019;75:208-219.

20. De Simoni MG, Perego C, Ravizza T, et al. Inflammatory cytokines and related genes are induced in the rat hippocampus by limbic status epilepticus. Eur J Neurosci. 2000;12(7):2623-2633.

21. Pascual V, Allantaz F, Arce E, Punaro M, Banchereau J. Role of interleukin-1 (IL-1) in the pathogenesis of systemic onset juvenile idiopathic arthritis and clinical response to IL-1 blockade. J Exp Med. 2005;201(9):1479-1486.

22. Doughty PT, Hossain I, Gong C, et al. Novel microwire-based biosensor probe for simultaneous realtime measurement of glutamate and GABA dynamics in vitro and in vivo. Sci Rep. 2020;10(1):12777.

23. Xiang J, Jiang Y. Antiepileptic potential of matrine via regulation the levels of gamma-aminobutyric acid and glutamic acid in the brain. Int $\mathbf{J}$ Mol Sci. 2013;14(12):23751-23761.

24. Walsh LA, Li M, Zhao TJ, Chiu TH, Rosenberg HC. Acute pentylenetetrazol injection reduces rat GABAA receptor mRNA levels and GABA stimulation of benzodiazepine binding with No effect on benzodiazepine binding site density. J Pharmacol Exp Ther. 1999;289(3):1626-1633.

25. Koshal P, Kumar P. Neurochemical modulation involved in the beneficial effect of liraglutide, GLP-1 agonist on PTZ kindling epilepsy-induced comorbidities in mice. Mol Cell Biochem. 2016;415(12):77-87.

26. Lacoste L, Bartolucci S, Lapointe J. Pentylenetetrazole inhibits glutamate dehydrogenase and aspartate aminotransferase, and stimulates GABA aminotransferase in homogenates from rat cerebral cortex. Can J Physiol Pharmacol. 1988;66(9):1135-1138.

27. Wang S, Cheng Q, Malik S, Yang J. Interleukin1beta inhibits gamma-aminobutyric acid type A (GABA(A)) receptor current in cultured hippocampal neurons. J Pharmacol Exp Ther. 2000;292(2):497-504.

28. Zhang R, Yamada J, Hayashi Y, Wu Z, Koyama S, Nakanishi H. Inhibition of NMDA-induced outward currents by interleukin-1beta in hippocampal neurons. Biochem Biophys Res Commun. 2008;372(4):816-820.

29. El-Missiry MA, Othman AI, Amer MA, Sedki M, Ali SM, El-Sherbiny IM. Nanoformulated ellagic acid ameliorates pentylenetetrazol-induced experimental epileptic seizures by modulating oxidative stress, inflammatory cytokines and apoptosis in the brains of male mice. Metab Brain Dis. 2020;35(2):385-399.

30. Kola PK, Akula A, Nissankara Rao LS, Danduga RCSR, Mohammad A, Ineedi S. Naringin in a combined therapy with phenytoin on pentylenetetrazole- 
induced kindling in rats. Epilepsy Behav. 2018;89:159-168.

31. Dorandeu F, Barbier L, Dhote F, Testylier G, Carpentier P. Ketamine combinations for the field treat- ment of soman-induced self-sustaining status epilepticus. Review of current data and perspectives. Chem Biol Interact. 2013;203(1):154-159. 